\title{
Leaf surface wetness in sorghum and resistance to shoot fly, Atherigona soccata: role of soil and plant water potentials
}

\author{
By P SOMAN, K F NWANZE, K B LARYEA, D R BUTLER and \\ Y V R REDDY \\ International Crops Research Institute for the Semi-Arid Tropics (ICRISAT), \\ Patancheru, Andhra Pradesh 502 324, India
}

(Accepted 27 July 1993)

\begin{abstract}
Summary
In experiments with potted plants, the relationships between soil matric potential, plant water potential and production of water droplets (leaf surface wetness) on the folded central whorl leaf of seedlings of sorghum genotypes that are either resistant or susceptible to shoot fly (Atherigona soccata) damage were investigated. Differences in soil matric potentials in the pots affected the plant water status, which in turn had profound effects on the production of water droplets on the central whorl leaf of the sorghum genotype susceptible to shoot fly. There was no consistent variation in the relationship between plant water potential and soil matric potential of resistant and susceptible sorghum genotypes. However, there was very little or practically no water droplets on the central whorl leaf of the resistant genotypes, indicating that the production of water droplets is not solely the result of internal water status of the plant. It is suggested that leaf surface wetness is genetically controlled and that an understanding of the mechanism by which water is transferred to the leaf surface will enhance breeding for resistance to shoot fly.
\end{abstract}

Key words: Leaf surface wetness, plant water potential, soil matric potential, Atherigona spp., Muscidae, shootfly

\section{Introduction}

The sorghum shoot fly Atherigona soccata Rondani (Muscidae: Diptera) is a serious pest of sorghum in Africa and India (Young \& Teetes, 1977). Shoot fly infestation results in the destruction of the growing point of 1-3 wk-old seedlings and the damage appears as characteristic "deadheart" symptom. Among the various options for shoot fly control, plant resistance is a particularly desirable management strategy. Several resistance factors have been identified in sorghum, one of which is the absence of water droplets on the upper surface of the unexpanded central whorl leaf of seedlings of resistant sorghum genotypes (Nwanze, Reddy \& Soman, 1990). The central whorl leaf is the path of a newly hatched larva as it moves from the oviposition site towards the growing point. Leaf surface wetness (LSW) has been associated with larval movement, survival of the sorghum shoot fly and deadheart formation. LSW is highly and significantly greater in shoot fly susceptible sorghum genotypes $\left(>4 \mathrm{mg}\right.$ of water leaf $\left.{ }^{-1}\right)$ than in resistant ones $\left(<1 \mathrm{mg}\right.$ of water leaf $\left.\mathrm{f}^{-1}\right)(\mathrm{Nwanze}$ et al., 1992).

(C) 1994 Association of Applied Biologists 
In an earlier study (Nwanze et al., 1992), we examined the dynamics of LSW and found that the seasonal variations in LSW were similar to those of shoot fly population and deadheart. In all three variables, there is a gradual increase with the onset of rains in June, resulting in a major peak in August. As the rains decrease towards the end of the main crop season in October, a decline in shoot fly population also takes place, and the lowest counts were observed from late March to June. This pattern was also closely associated with relative humidity. However, the results from our earlier study suggested that LSW originates from the plant and that it is not the result of atmospheric condensation within the plant whorl. We further postulated that there could be differences between sorghum genotypes in the genetic potential for the production of LSW.

In a preliminary experiment with potted seedlings of shoot fly susceptible genotypes, we observed that subjecting plants to water stress resulted in reduced LSW. Plant water potential (PWP) is affected by available soil water and the evaporative demand of the atmosphere. In an earlier study, Nwanze et al. (1992) suggested that LSW originates from the plant. Seasonal changes in soil water status would affect PWP and may account, to some extent, for the seasonal changes in LSW. We hypothesise that LSW will be affected by changes in PWP. The latter can be varied by manipulating the soil matric potential (SMP) in a setup with a constant evaporative demand. We tested this hypothesis using different soil moisture regimes in order to investigate the link between soil and plant water relations and the production of LSW.

We conducted several pot experiments with different soil moisture treatments in order to obtain a range of soil moisture regimes and different levels of plant water potential. We also compared the relationship between LSW and PWP for shoot fly susceptible and resistant sorghum genotypes.

\section{Materials and Methods}

\section{Soil and plant material}

Sorghum plants were grown in $18-\mathrm{cm}$ diameter plastic pots containing a soil and peat mixture (4:1). No additional fertiliser was applied and all plants were grown outside. For experiments on the relationships between SMP, PWP and LSW, three sorghum genotypes were used; shoot fly-resistant IS 18551, moderately resistant IS 1054 and susceptible CSH 5 .

\section{Soil water status in potted soil under declining water regimes}

A preliminary experiment was conducted to determine the trend in declining soil water content in our experimental pots as a function of time after irrigation was terminated. This information is needed for subsequent experimentation on PWP and SMP. Thirty pots were weighed, filled with potting mixture, slightly compacted to the same level, re-weighed and saturated with water. They were then left to drain for $24 \mathrm{~h}$ on a wire-mesh bench. They were numbered, weighed again and randomly grouped into six treatments of five pots/ treatment. These treatments represent six soil moisture regimes. Subsequently, on 1, 2, 4, 6, 7 and 11 days after irrigation (DAI) was terminated, one set of pots (i.e. one treatment) was weighed and discarded. The last set of five pots (treatment 6) which had undergone 11 days of drying was weighed on the 12th day. Data were used to calculate the volumetric $\left(\mathrm{cm}^{3} / \mathrm{cm}^{3}\right)$ water contents. 


\section{Leaf surface wetness and plant water potential of potted seedlings under different soil water status}

\section{Experiment I}

Pots were initially treated as described above and saturated with water on 12 March 1991 . After draining, seeds of shoot fly susceptible sorghum genotype, $\mathrm{CSH} 5$, were sown at the rate of six seedlings per pot. The pots were fully irrigated every day until seedling emergence which occurred 5 days after sowing (DAS). Pot weights were recorded. The pots were then randomly grouped into 13 sets of six pots each. Thereafter, beginning one day after emergence (1 DAE), i.e. 6 DAS, irrigation was successively terminated in one set of six pots while the remaining sets were irrigated. This procedure was repeated for 12 days giving a total of 13 moisture treatment levels. The choice of 13 moisture levels and the procedure used ensured that all plants reached the fifth leaf stage at 12 days after emergence (DAE). The 13th treatment (T13) was the wettest (no moisture stress), T12 experienced only one day of declining soil water content, while $\mathrm{T} 1$ was the driest treatment that did not have any irrigation for 12 days. In order to maintain a fairly reproducible soil water status until the day irrigation was terminated, each pot was weighed, and water was added to restore the previous day's weight.

On the 13th day, the final soil moisture content and matric potential (i.e. the component of water potential due to capillary forces and the interaction of water with soil colloidal materials) in all pots were determined using the filter paper method (Graecen, Walker \& Cook, 1987). In this method, Whatman no. 42 filter paper is equilibrated with soil water either through the vapour phase or combined liquid and vapour phase flow. The soil water potential is determined by measuring the water content of the filter paper and using a moisture release curve to determine the water potential of the paper. If moisture exchange is entirely in the vapour phase, then the potential measured by the paper is the sum of soil matric and osmotic potentials. If exchange is through liquid phase flow as happened with the experiments described in this paper, then it is the matric potential (Campbell \& Gee, 1986).

\section{Measurement of LSW and PWP}

Quantitative measurements of LSW described by Nwanze et al. (1992), were taken on three randomly selected seedlings from each pot in each treatment between 0200 and 0600 $\mathrm{h}$, a period during which LSW is known to be highest.

In order to ascertain the time when PWP is less negative (i.e. when the plant water status is under less tension, a condition which will favour production of LSW), three measurements of PWP on individual seedlings were taken at 1800,2300 and $0200 \mathrm{~h}$ using a pressure chamber (PMS Instrument Co., Oregon, USA). At each measurement, three seedlings in separate pots were randomly selected from each moisture treatment. Each seedling was cut at the soil surface, immediately placed in the chamber with the axis of the seedling held in a split rubber cork and PWP measured as described by Scholander, Hammel \& Bradstreet (1965).

\section{Experiment II}

In a second experiment started on 28 August 1991 to increase the range of PWP, we extended the driest treatment to 20 days after termination of irrigation. However, to ensure the establishment of seedlings in the driest treatments, and that all seedlings reached 10 DAE together, we pre-germinated the seeds in an incubator maintained at $31^{\circ} \mathrm{C}$ and sowed them into pots on the 9th day after starting the moisture treatments. Thus T1-T9 received 


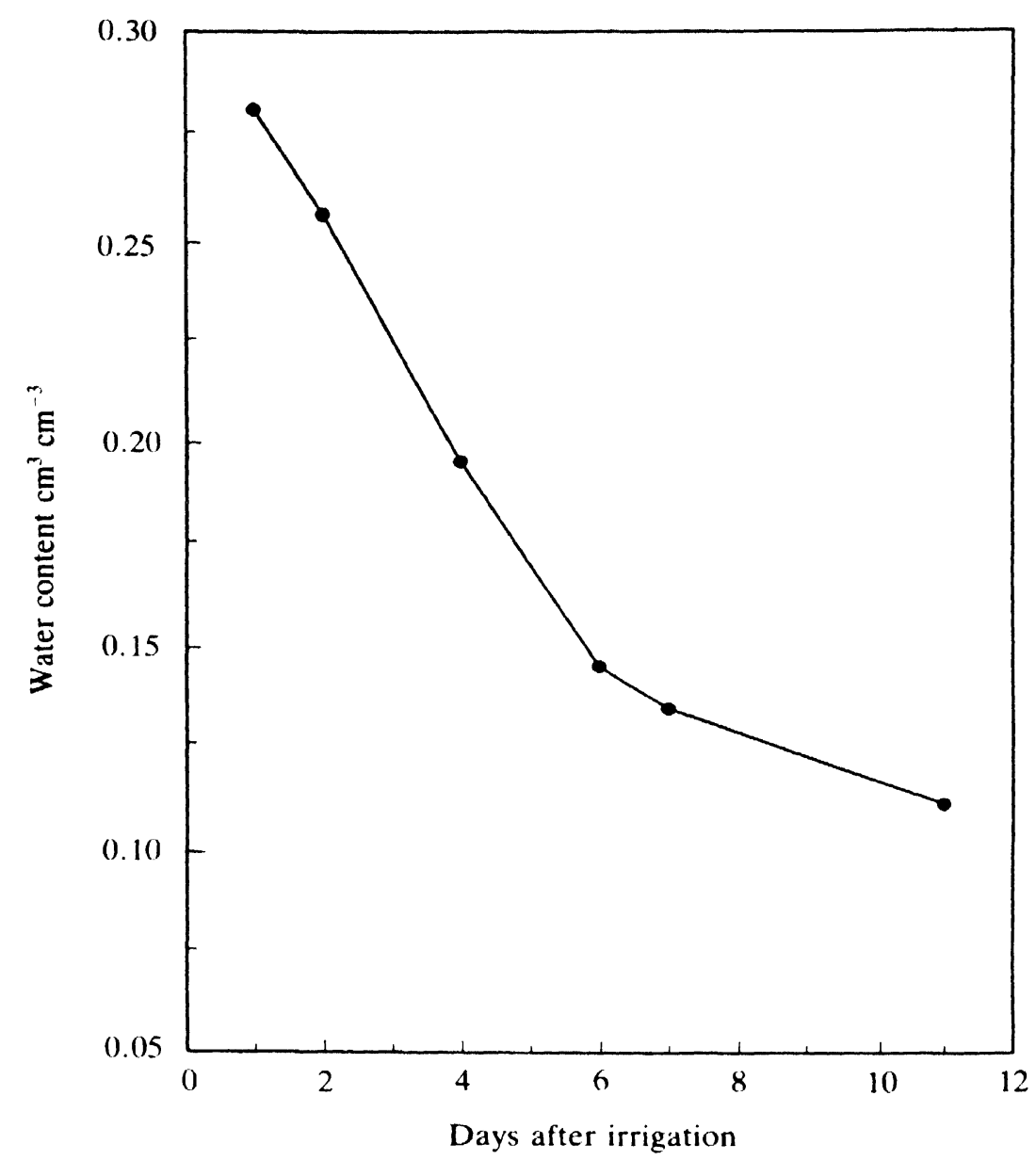

Fig. 1. Depletion of soil water in pots in the different treatments from the days after irrigation (DAI) was terminated in the preliminary experiment (SE bars are smaller than the symbols).

no further irrigation while other treatments followed the same procedures as described above for obtaining a declining range in soil water status. All other procedures were the same as in Experiment I, except that PWP was measured only twice, at 1400 and $1800 \mathrm{~h}$.

\section{$L S W-P W P$ relationship in shoot fly resistant and susceptible genotypes}

\section{Experiment III}

There were only three soil moisture levels in this experiment which was started on 23 September 1991: T1 with no irrigation after 5 DAS (severe stress); T2 with no irrigation after 12 DAS (moderate stress) and T3 with no moisture stress. Three sorghum genotypes were used: shoot fly resistant IS 18551 , moderately resistant IS 1054 and susceptible CSH 5. All other procedures were the same as in Experiment I except that PWP was measured only once at $1400 \mathrm{~h}$.

\section{Results}

\section{Variation in soil moisture status}

In the preliminary experiment, the volumetric moisture contents decreased quickly within the first $6 \mathrm{DAI}$. The rate of decline in the moisture content then slowed down reaching a 


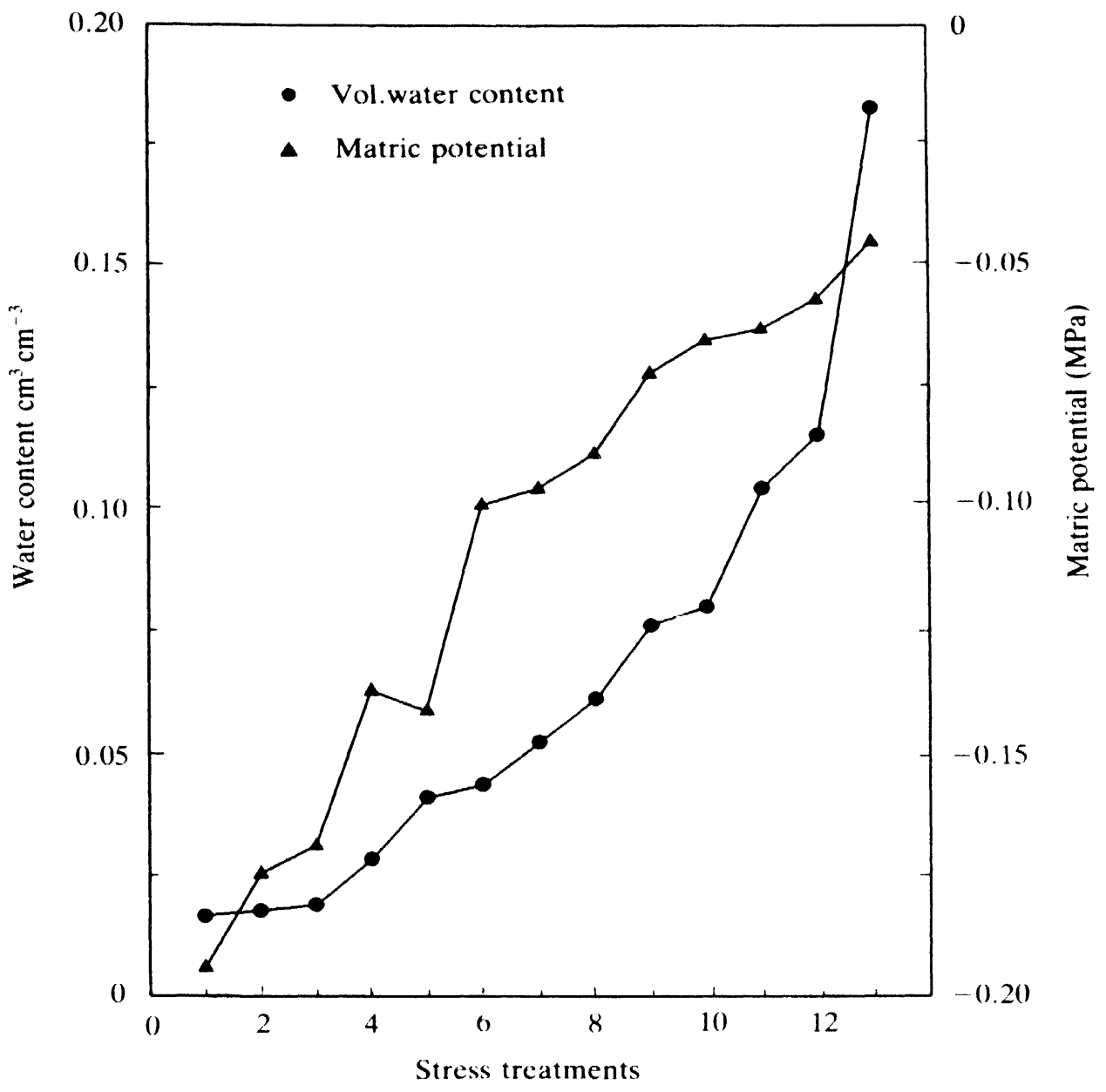

Fig. 2. Soil water contents and matric potentials of the 13 stress treatments in Experiment I measured on 13 DAE (i.e. 18 DAS) (SE bars are smaller than symbols).

mean of $0.111 \pm 0.002 \mathrm{~cm}^{3} \mathrm{~cm}^{3}$ at $11 \mathrm{DAl}$ (Fig. 1). Fig. 2 presents the soil water contents measured on 13 DAS on the 13 stress treatments in Experiment 1 . The moisture contents ranged from a mean of $0.017 \pm 0.003 \mathrm{~cm}^{3} \mathrm{~cm}^{-3}$ in the most stressed treatment to a mean of $0.183 \pm 0.006 \mathrm{~cm}^{3} \mathrm{~cm}^{3}$ in the least stressed treatment or wet soil. These moisture contents correspond to mean soil moisture suctions of $0.155 \pm 0.003 \mathrm{MPa}$ in the most stressed treatment to $0.006 \pm 0.0004 \mathrm{MPa}$ in the least stressed treatment.

Variation in plant water potential ( $P W P)$

Variations in soil matric potentials (SMP) in Experiment I affected plant water potentials as shown in Fig. 3. In Experiment I, PWP varied significantly $(P<0.05)$ between time of measurements (Figs $4 a, b, c$ ). At $1800 \mathrm{~h}$, PWP was least in all treatments and at 2300 and $0200 \mathrm{~h}, \mathrm{PWP}$ showed recovery. Differences in measurements made between 2300 and 0200 $\mathrm{h}$ were not significant. Plant water potential at $1800 \mathrm{~h}$ ranged from $-1.2 \mathrm{MPa}$ for T1 to $-0.37 \mathrm{MPa}$ for T13. The plant water potential recovered to -0.75 in $\mathrm{T} 1$ and $-0.35 \mathrm{MPa}$ in $\mathrm{T} 13$ respectively by $0200 \mathrm{~h}$.

In Experiment II, PWP was $-2.25 \mathrm{MPa}$ at $1400 \mathrm{~h}$ and $-1.47 \mathrm{MPa}$ at $1800 \mathrm{~h}$ for T1 (the driest treatment). It was $-0.17 \mathrm{MPa}$ at $1400 \mathrm{~h}$ and $-0.57 \mathrm{MPa}$ at $1800 \mathrm{~h}$ for $\mathrm{T} 20$ (the wettest treatment). The overall difference in PWP between 1400 and $1800 \mathrm{~h}$ was highly significant 


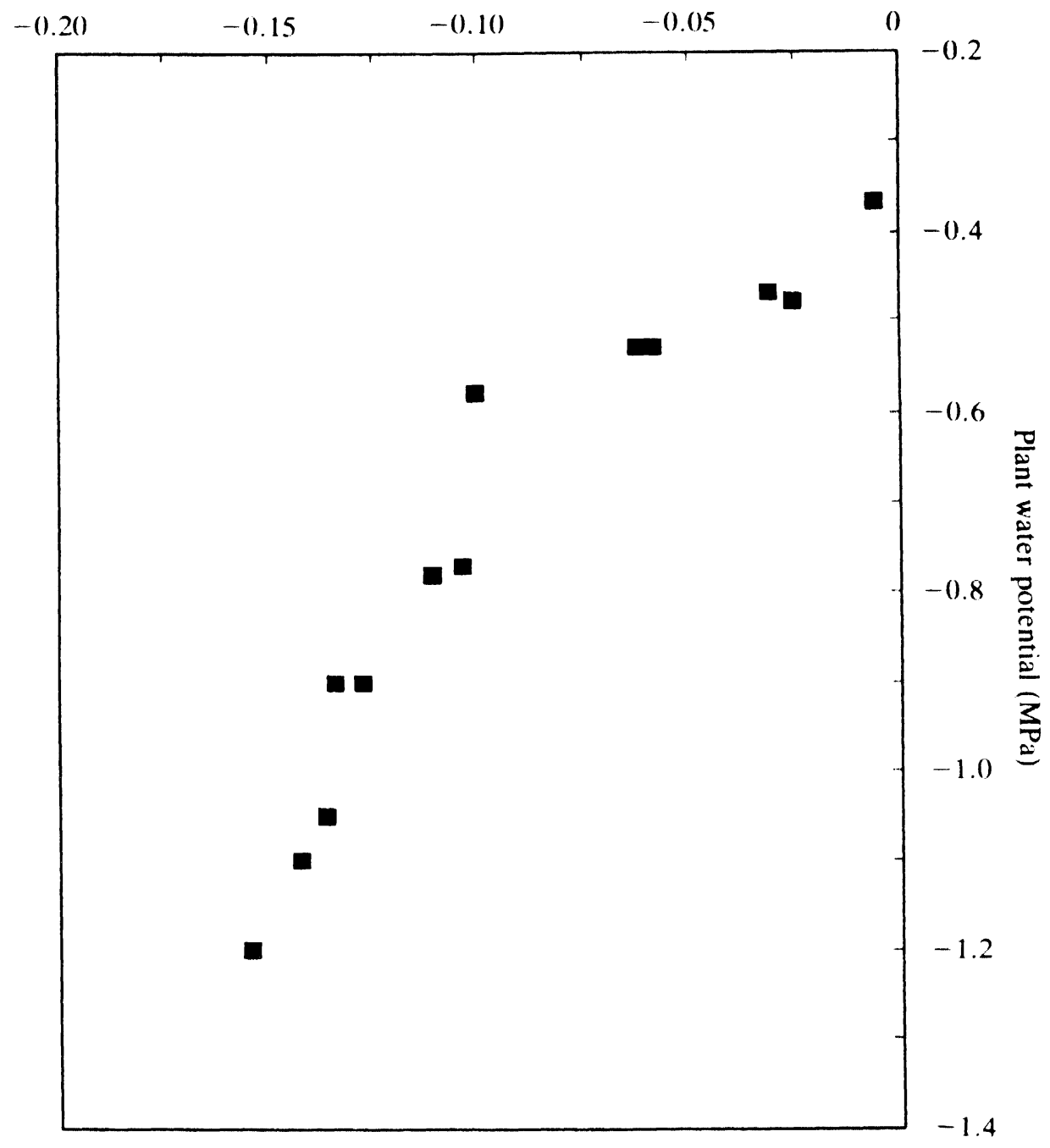

Fig. 3. Relationship between plant water potential and soil matric potential in Experiment 1.

$(P<0.001)$ and significant differences were found $(P<0.001)$ among the various moisture treatments.

In Experiment III, the genotypic differences in the LSW-PWP relationship were significant at $1400 \mathrm{~h}$. The three genotypes did not respond similarly to the moisture treatments thus exhibiting a significant $(P<0.01)$ genotype $\times$ treatment interaction (Fig. 5). The differences in the relationship between PWP and SMP for the three genotypes were not consistent (Fig. 6 ). At $\mathrm{SMP}=0$ (wet soil), there were significant differences between the genotypes. Similarly, in the dry range (SMP > $-0.15 \mathrm{MPa}$ ), the influence of SMP on PWP in IS 1054 and CSH 5 was significantly different from that in IS 18551. However, when the soil was in the moist state (i.e. $0.1<$ SMP $<0.15 \mathrm{MPa}$ ), the influence of SMP on PWP in all the three genotypes was similar.

\section{Variation in leaf surface wetness ( $L S W$ )}

Leaf surface wetness decreased with increasing water stress in all experiments (Table 1 , Fig. 4) and this relationship holds particularly for CSH 5 (Fig. 7). For example, in 

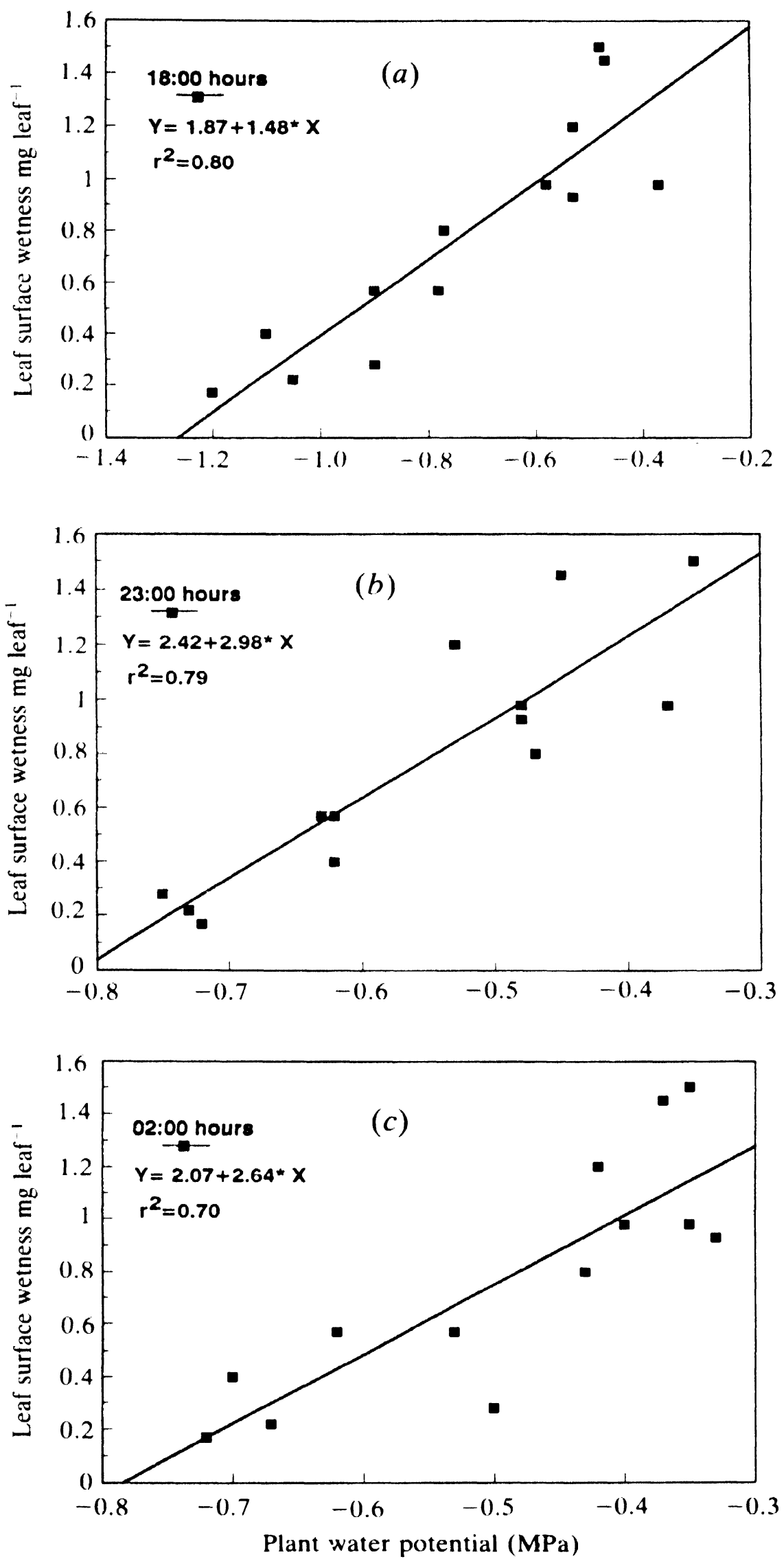

Fig. 4. The relationship between leaf surface wetness and plant water potential at 1800,2300 and $0200 \mathrm{~h}$ respectively for the shoot fly susceptible genotype CSH 5 in Experiment $\mathbf{I}$. 


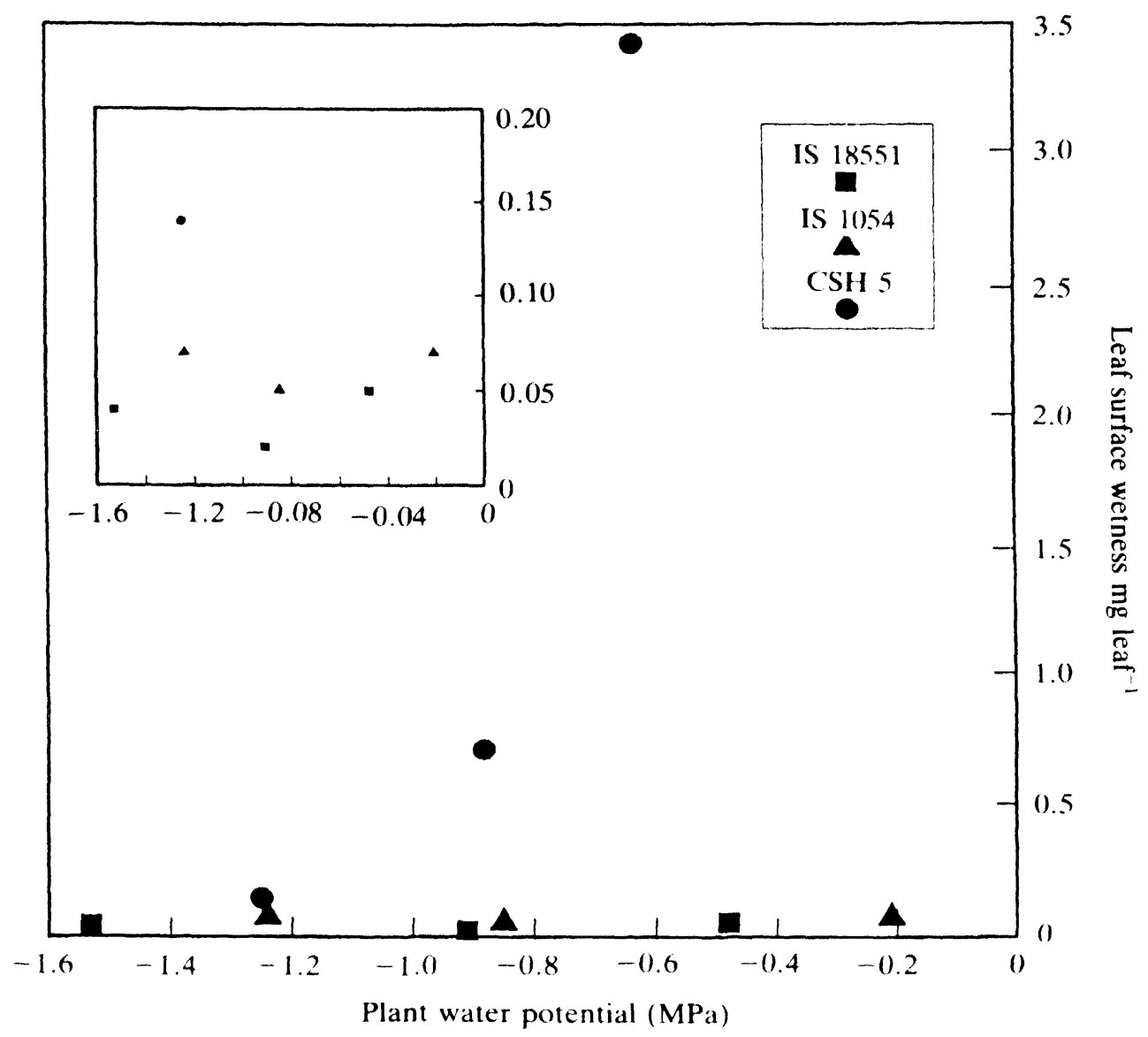

Fig. 5. The relationship between leaf surface wetness and plant water potential for two shoot fly resistant genotypes. IS 18551 and IS 1054 and a susceptible genotype, CSH 5 in Experiment III

Experiment I, the amount of LSW on T13 was $0.98 \mathrm{mg} \mathrm{leaf}^{-1}$ while there was only $0.17 \mathrm{mg}$ leaf $^{-1}$ on T1. It has been observed that the amount of LSW changes with season, and maximum LSW appears in the month of August (Nwanze et al., 199()). The absolute amounts of LSW found in the three experiments in the wet (unstressed) treatment varied. In Experiment II conducted during August-September, LSW on CSH 5 ranged from 5.9 $\mathrm{mg} \mathrm{leaf}^{-1}$ in T20 to $0.06 \mathrm{mg} \mathrm{leaf}^{-1}$ in T1. In Experiment III conducted during September October, LSW on T3 (unstressed) was $3.42 \mathrm{mg} \mathrm{leaf}^{-1}$ and on T1 was $0.14 \mathrm{mg} \mathrm{leaf}^{-1}$ for CSH 5 (Table 2).

In Experiment I, LSW was linearly related to PWP measured at 1800, 2300 and $0200 \mathrm{~h}$ (Figs $4 a, b, c)$, indicating the overall association of LSW with plant water status. In Experiment II, the linearity of the relationship extended up to the lowest amount of LSW that could be measured at $1400 \mathrm{~h}$ when LSW was lowest at PWP of -2.0 MPa (Fig. 7).

In Experiment III, the LSW-PWP relationship was maintained for the susceptible genotype whereas for the two resistant genotypes, there was no variation in LSW despite changes in PWP (see insert in Fig. 5). The decrease in soil moisture status resulted in the decline of PWP in both susceptible and resistant genotypes. The resistant genotypes are known for the absence of LSW (Nwanze et al., 1990) but it is clear that this is not due to unexpectedly stable plant water status in relation to the soil moisture status. 
Soil matric potential (MPa)

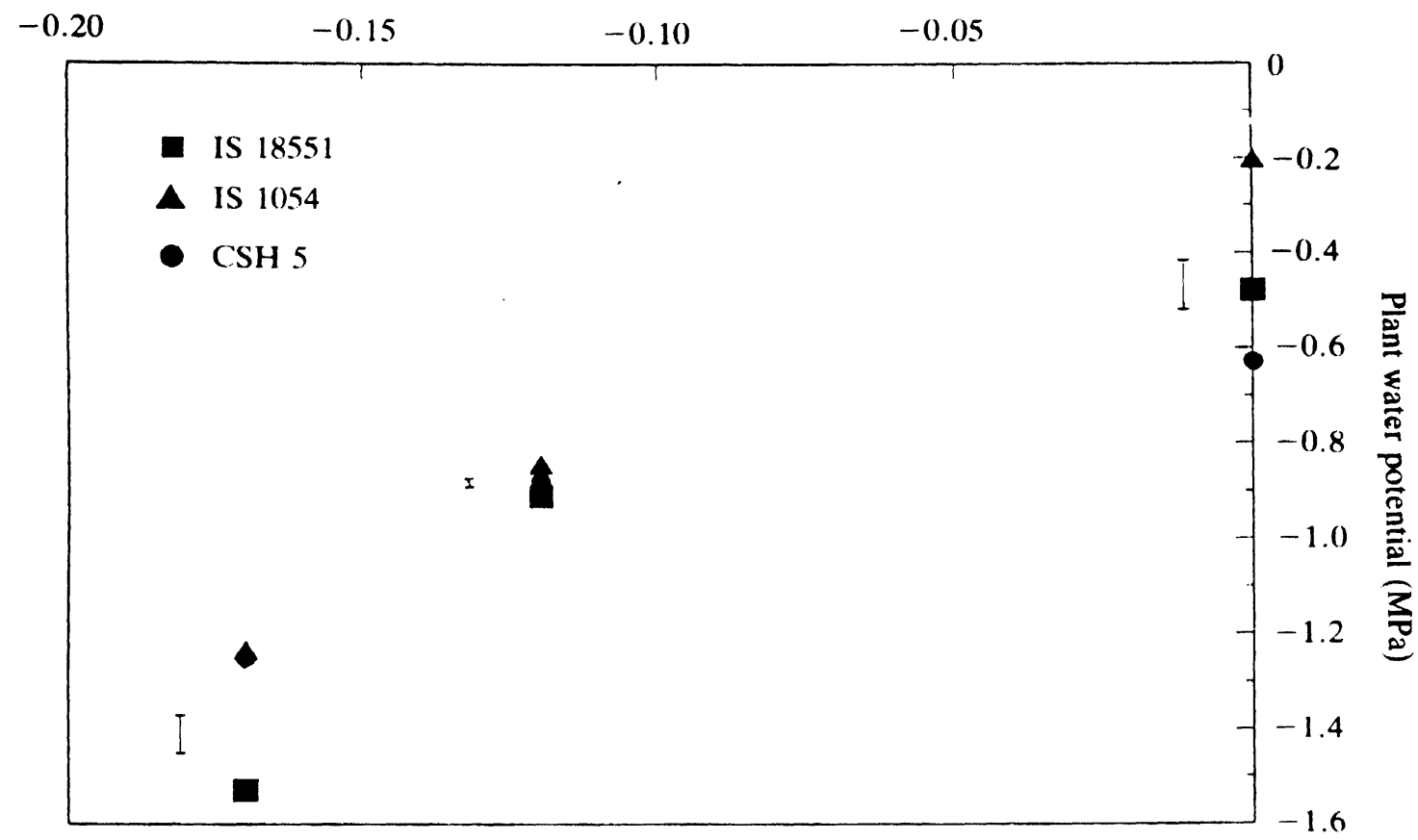

Fig. 6. Relationship between plant water potential and soil matric potential for the three genotypes in Experiment III.

Table 1. Leaf surface wetness ( $L S W$ ) measured between 0200 to 0600 hours for the different treatments in Experiment I and II. Each value is the mean ( \pm standard error) of six (Experiment I) and eight (Experiment II) measurements

Treatments

1
2
3
4
5
6
7
8
9
10
11
12
13
14
15
16
17
18
19
20

Leaf surface wetness $\mathrm{mg}$ leaf ${ }^{1}$ Experiment I
$0.17 \pm 0.056$
$0.40 \pm 0.153$
$0.22 \pm 0.048$
$0.28 \pm 0.070$
$0.57 \pm 0.292$
$0.57 \pm 0.136$
$0.80 \pm 0.191$
$0.98 \pm 0.204$
$0.93 \pm 0.270$
$1.20 \pm 0.227$
$1.45 \pm 0.318$
$1.50 \pm 0.190$
$0.98 \pm 0.196$

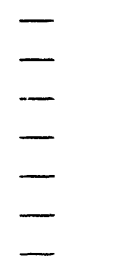

Experiment II

$$
\begin{aligned}
& 0.06 \pm 0.037 \\
& 0.11 \pm 0.034 \\
& 0.21 \pm 0.067 \\
& 0.23 \pm 0.052 \\
& 0.23 \pm 0.059 \\
& 0.24 \pm 0.073 \\
& 0.25 \pm 0.060 \\
& 0.60 \pm 0.299 \\
& 0.90 \pm 0.304 \\
& 0.98 \pm 0.286 \\
& 1.06 \pm 0.165 \\
& 1.39 \pm 0.280 \\
& 2.14 \pm 0.340 \\
& 2.29 \pm 0.358 \\
& 2.26 \pm 0.393 \\
& 2.99 \pm 0.595 \\
& 3.54 \pm 0.523 \\
& 4.76 \pm 1.522 \\
& 4.54 \pm 1.116 \\
& 5.89 \pm 1.794
\end{aligned}
$$


Table 2. Leaf surface wetness ( $L S W$ ) measured between 0200 to 0600 hours for the different treatments in Experiment III. Each value is the mean ( \pm standard error) of 10 measurements.

Leaf surface wetness $\mathrm{mg}$ leaf ${ }^{\prime}$

Treatments

1
2
3
IS-18551

$0.05 \pm 0.016$
$0.02 \pm 0.013$
$0.05 \pm 0.021$
IS-1054

$$
\begin{aligned}
& 0.07 \pm(.016 \\
& 0.05 \pm 0.016 \\
& 0.08 \pm 0.028
\end{aligned}
$$

CSH-5

$0.14 \pm 0.041$

$0.71 \pm 0.186$

$3.42 \pm 0.738$

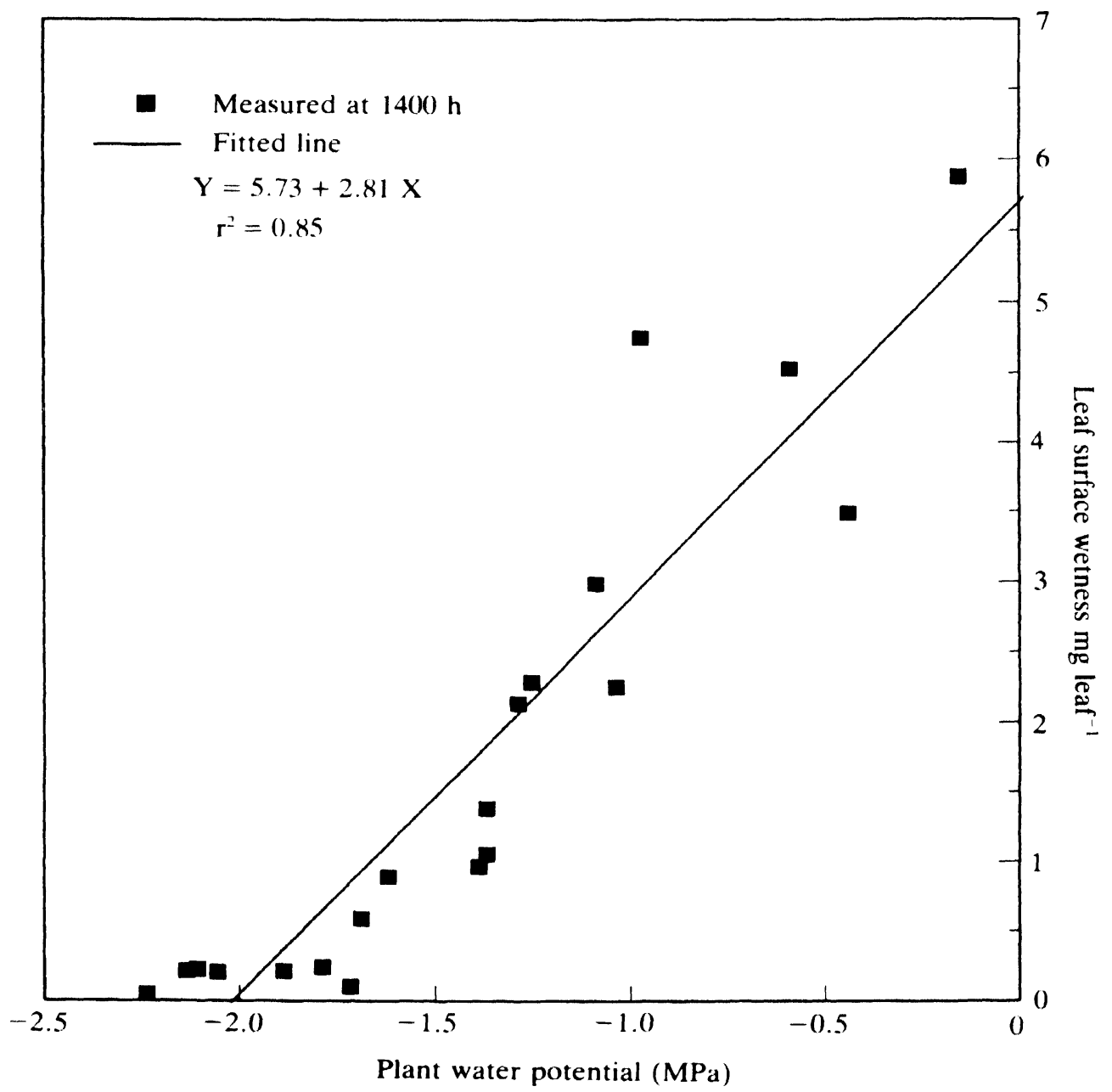

Fig. 7. The relationship between leaf surface wetness and plant water potential for the shoot fly susceptible genotype, CSH 5 in Experiment II.

\section{Discussion}

In all three experiments soil moisture differences resulted in variations in soil matric potentials (e.g. Fig. 2) which affected plant water potentials (e.g. Fig. 3). The procedure of stopping irrigation to create progressive stress provided an excellent method to obtain a large range of soil and plant water deficits. 
Changes in the soil and aerial environments alter the water relations of plants. Plant water potential by definition is the difference between the chemical potential of the water in the plant and that of pure water at zero matric potential (Slatyer \& Taylor, 1960) and it is generally used as a measure of plant water status. In the soil plant atmosphere continuum there is a continuous flow of water from the soil (source) to the atmosphere (sink) through the plant and water moves along a gradient of potential. In any particular day, this gradient will normally be maximum in mid-afternoon when the demand for evaporation is greatest and it will be minimum just before sunrise when transpiration is least. Continuous water uptake from the soil at night tends to equilibrate the soil and plant water potentials. However, when the soil dries and limits the supply of water to the plants, the night-time recovery of PWP is incomplete so the plant becomes water stressed. In the present study this phenomenon induced different plant water potentials according to the soil water status.

The plant water potential was lowest at $1400 \mathrm{~h}$ and represents the maximum demand of the plant for water from the soil. Measurements later in the day showed recovery of PWP, with maximum values at $0200 \mathrm{~h}$ (the last time of measurements). This pattern of recovery was similar in the water-stressed and the non-stressed plants though the rates of recovery were different. The water potential gradient between plant and soil will determine the rate of water absorption and movement into the plant. In the present study, PWP was related to the quantity of water on the leaf surface of the susceptible genotype. Theoretically, we would only expect water to exude onto the leaf surface if the water potential near the surface is zero. This may occur with specially adapted cells as in the case of guttation. However, in this study water appeared on the surface when PWP was well below zero (highly negative). Therefore the actual mechanism of transferring water from inside to outside of the leaf appears not to follow the classic water relations principle. We did not measure the water potential of the leaf on which LSW was measured, but because LSW appears to some extent in severely stressed plants, it is unlikely that the water potential of the whorl leaf becomes zero. Further studies are in progress to elucidate the mechanism of water transfer which supplies LSW.

Nwanze et al. (1992) showed that the LSW does not condense from the atmosphere. They deduced that water on the unexpanded whorl leaf must have originated from the plant itself. The close agreement here between LSW and PWP supports this inference. Because stomata are shut at night and the cuticular conductance is negligible (data not reported here), there would be little transfer of water vapour from the leaf. Even if water vapour is transferred, it is unlikely that water will condense on the surface since the microclimatic conditions indicate that evaporation would still occur at the time of maximum LSW accumulation (Nwanze et al., 1992). Further studies are planned to investigate the source and path of LSW.

In resistant genotypes, PWP varied in a similar way to susceptible genotypes with variation in soil matric potentials between -0.1 and $-0.15 \mathrm{MPa}$. In either the wet range $(\mathrm{SMP}=0)$ or the dry range (SMP $>-0.15 \mathrm{MPa})$ the influence of SMP on PWP for IS 18551 was different from IS 1054 and CSH 5 (Fig. 6). However, LSW was either absent or very little on the surface of the central leaf whorl of the resistant genotypes and was not related to the variation in PWP. This lack of relationship between LSW and PWP in the resistant genotypes despite the changes in PWP indicates that LSW is not the result of internal water status of the plant alone. The mechanism by which water is transferred to the leaf surface in the susceptible genotype appears to be lacking in the resistant genotypes. This implies that the supply of LSW may be genetically controlled. Since LSW is highly associated with resistance to shoot fly (Nwanze et al., 1990) an understanding of the mechanism by which LSW is produced will contribute towards successful breeding for resistance to this insect. 


\section{Acknowledgements}

We wish to thank Mr R Sudi for assisting with the graphs and Mr R Jayachandran for his critical review of the manuscript during its final stages of preparation.

This paper was submitted as Journal Article No. 1441 by the International Crops Research Institute for the Semi-Arid Tropics (ICRISAT).

\section{References}

Campbell G S, Gee G W. 1986. Water Potentials: Miscellaneous Methods. In Methods of Soil Analysis, Part 1, Physical and Mineralogical Methods, Second Edition, pp. 619-633. Ed. A Klute. Madison, Wisconsin, USA: American Society of Agronomy, Inc., Soil Science Society of America, Inc.

Greacen E L, Walker G R, Cook P G. 1987. Evaluation of the filter paper method for measuring soil water suction. In Proceedings of International Conference on measurement of soil and plant water status, Centennial of Utah State University, 6-10 July 1987, Logan, Utah, USA, Vol. 1, pp. 137143.

Nwanze K F, Reddy Y V R, Soman P. 1990. The role of leaf surface wetness in larval behaviour of the sorghum shoot fly, Atherigona soccata. Entomologia experimentalis et applicata 56:187-195.

Nwanze K F, Sree P S, Butler D R, Reddy Y V R, Soman P. 1992. The dynamics of leaf surface wetness of sorghum seedlings in relation to resistance to the shoot fly, Atherigona soccata. Entomologia experimentalis et applicata 64:151-160.

Scholander P F, Hammel H T, Bradstreet E D. 1965. Sap pressure in vascular plants. Science 148:339346.

Slatyer R O, Taylor S A. 1960. Terminology in plant soil-water relations. Nature (London) 187:922. Young W R, Teetes G L. 1977. Sorghum Entomology. Annual Review of Entomology 22:193-218.

(Received 10 November 1992) 